\title{
Possible Protective Mechanisms of Sitagliptin against Isoproternol Induced Myocardial Injury in Rat
}

\author{
Wesam M El-Bakly ${ }^{1}$
}

${ }^{1}$ Pharmacology Department, Faculty of Medicine, Ain Shams University, Cairo, Egypt

\begin{abstract}
Sitaglebtin, dipeptidyl peptidase 4 inhibitors, has been investigated and proved to improve triglycerides, low density lipoprotein and blood pressure, which are important risk factors for cardiovascular diseases. Aim: The present study was designed to investigate the potential protective effect of sitaglebtin in isoproterenol induced myocardial injury. Further assessment was done to address the cardioprotective mechanism. Method: Male Wister rats were treated with sitaglebtin (30 $\mathrm{mg} / \mathrm{kg} /$ day for 2 weeks by gavage) and/ or isoproterenol ( $85 \mathrm{mg} / \mathrm{kg}$; i.p. 24 hours apart at day $14^{\text {th }}$ and $15^{\text {th }}$ of the experiment). Results: Isoproternol induced a significant ECG changes, several pathological changes and elevated cardiac enzymes. These changes were significantly attenuated by pre-treatment of rats with sitaglebtin. As a marker of oxidative stress, isoproterenol caused significant decrease in reduced glutathione level and superoxide dismutase with increase in malondialdhyde compared to the control group. Sitaglebtin pretreatment restored these markers toward normal values. Energy decline was assessed by measuring ATP/ADP, which decreased significantly in isoproterenol group and significantly increased by sitaglebtin pretreatment. Isoproternol caused inflammatory effects indicated by up-regulation of tumor necrosis factor- $\alpha$ expression in the myocardial tissue. Sitaglebtin also counteracted inflammatory cell infiltration, other histopathological changes, and the overexpression tumor necrosis factor- $\alpha$ in myocardial tissue. Collectively, these findings suggest that sitaglebtin, an anti-diabetic agent, has cardioprotective effect against isoproterenol induced myocardial injury that could be through antioxidant properties, TNF- $\alpha$ inhibition, and an enhancement of myocardial energy state.
\end{abstract}

Keywords Isoproternol (ISO); Sitagliptin (SL); ATP/ADP, oxidative stress; myocardium

\section{Introduction}

$\mathrm{T}$ The cardiac problems in patients with diabetes is a major cause of morbidity and mortality (Laing et al., 2003; Snell-Bergeon and Wadwa, 2012), it affects $50-60 \%$ of persons with type 2 diabetes (Duckworth et al., 2009). Diastolic dysfunction is the common effect of type 2 diabetes on cardiovascular system (Patil et al., 2011). Insulin resistance is associated with chronic low-grade inflammation, which is predisposing to hypertension and chronic heart failure (Shim et al., 2006; El-Bassossy et al., 2015). So an antidiabetic agent that could improve cardiovascular outcomes in these patients is essentially to be known.

Isoproterenol (ISO), a $\beta$-receptor agonist, administration caused significant left ventricular hypertrophy and fibrosis, and decreased left ventricular diastolic function. ISO-treated rats are an appropriate model of diastolic dysfunction (Sumita Yoshikawa et al., 2012). It depletes the energy source of myocytes, which results in irreversible cellular damage and ultimately infarct-like necrosis (Murugesan and Manju, 2013).

Glucagon-like peptide-1 (GLP-1) is secreted primarily by the intestinal entero-endocrine cells (Nauck et al., 1993). GLP-1 analog showed protective effects on high-fat diet-induced insulin resistance, inflammation (Apaijai et al., 2012), and myocardial infarction (Arakawa, et al., 2010). It improve energy metabolism by the intake of glucose to myocytes (Barakat et al., 2011). GLP-1 also activates c-AMPdependent protein kinase, thus enhancing L-type $\mathrm{Ca}^{2+}$ current in isolated cardiomyocytes (Nikolaidis et al., 2004; Anagnostis et al., 2011). It is degraded by dipeptidyl peptidase-4 (DPP4) with a very short half-life (2 to $3 \mathrm{~min}$ ) (Xiao et al., 2011). Recent experimental studies showed the protective effect of DPP4 inhibitors in hypertension (Pacheco et al., 2011), heart failure (Chaykovska et al., 2011), and myocardial infarction (Miki et al. 2012). 
Sitagliptin (SL) was the first DPP-4 inhibitor marketed in the United States in 2007 . Vildagiptin, was the second approved in Europe and other countries, followed by sitagliptin in 2009 (Miki et al., 2012). DPP-4 inhibitors have been investigated and proved to improve triglycerides, low density lipoprotein cholesterol, high density lipoprotein cholesterol, and blood pressure, which are important risk factors for cardiovascular diseases (Drucker et al., 2010). SL specifically has been approved by the FDA. It can be used as a single therapy or combined with metformin or glitazone to treat type 2 diabetes (Aschner et al., 2006; Charbonnel et al., 2006).

Therefore, the goal of the present study was designed to investigate the possible protective effects of SL against ISO-induced myocardial toxicity in rat. Moreover, to explore the role of oxidative stress, tumor necrosis factor (TNF)- $\alpha$, as well as the energy decline as possible mechanisms.

\section{Material and method}

\section{Drugs and chemicals}

Isoproterenol (ISO) was purchased as powder rom Sigma Chemicals (USA). Isoproterenol was dissolved in saline. Sitagliptin (Januvia ${ }^{\circledR}$ tablet) was obtained from Merck Sharp \& Dohme Ltd.

\begin{abstract}
Animals
Thirty-two Male Wister rats weighed 200-220g were obtained from the Holding Company for Biological Products \& Vaccines VACCERA, Egypt. The chow was acquired from Meladco for Animal Food, Egypt. Pellets and tap water were provided ad libitum. Temperature was maintained at $25^{\circ} \mathrm{C}$. A $12 / 12 \mathrm{~h}$ light/dark cycle was maintained. Rats were allowed at least 1 week to acclimatize to the lab conditions. All procedures were done according to European Directive 2010/63/EU and guidelines of ethical Committee, faculty of Medicine, Ain Shams University.
\end{abstract}

\section{Study Design}

Rats were allocated into four groups $(n=8)$ and treated for 15 days: vehicle control group, SL group (oral Sitagliptin $30 \mathrm{mg} / \mathrm{kg} /$ day), ISO group (intraperitoneal isoproterenol $85 \mathrm{mg} / \mathrm{kg} /$ day, twice at an interval 24 hours on the 14th and 15th day) (Murugesan and Manju, 2013) and ISO-SL group.SL concentrations were selected based on a previous report which showed its effectiveness in cardio-protection in obese insulin resistant rats (Chen et al., 2011; Apaijai et al., 2013).

Twenty-four hours after last injection with ISO, assessment of electrocardiograph under urethane anesthesia (1.2g/kg; Sigma -Aldrich) was done. After blood sampling from the retro-orbital venous plexus, it is allowed to clot and serum was separated by centrifugation at $3000 \mathrm{~g}$ for $15 \mathrm{~min}$ for biochemical assessment. Then rats were killed. The heart were dissected out, weighed and immersed in ice-cold saline or fixed in $8 \%$ buffered formalin for histopathological examination.

\section{ECG assessment}

By using ECG apparatus CardiMax FX-7102, USA, Electrocardiography (ECG) was recorded $24 \mathrm{~h}$ after
ISO injection. RR interval, heart rate and ST segment deviations were measured. ECG recording speed was $25 \mathrm{~mm} /$ second.

\section{Cardiotoxicity markers}

Heart index was calculated according to the formula: (heart weight/body weight) $\times 100$ Creatine kinase-MB and troponine I were determined using an enzymelinked immunosorbent assay (ELISA) developed by Life Diagnostics Inc. West Chester PA, USA, according to the manufacturer's instructions.

\section{Assessment of oxidative stress markers}

To assess the oxidative stress, the tissue level of, SOD, GSH and MDA were measured in cardiac homogenate of the different treated groups. SOD activities in the cardiac samples were assessed using assay kits (Trevigen, Inc., USA) according to the manufacturer's instructions. GSH was assessed according to the method of Ellman (Ellman, 1959). Also, MDA was measured according to the method of Mihara and Uchiyama (Mihara and Uchiyama, 1978).

\section{Assessment of myocardial nucleotides}

Hearts were homogenized in $6 \%$ perchloric acid. The clear supernatant was then neutralized by potassium hydroxide and used for determination of myocardial ATP and ADP by using HPLC (Kontron, 322, Sebai, Italy), C18 hypersil column and UV detector at $254 \mathrm{~nm}$ (Neri et al., 1986).

\section{Assessment of myocardial TNF- $\alpha$}

Myocardial TNF- $\alpha$ was assessed immune-histochemical. Paraffin embedded heart tissue sections of 3 micron thickness were prepared. The sections were stained with ready to use primary antibody (rabbit polyclonal antibody to rat TNF- $\alpha$ (US Bioogical, USA). Hematoxylin was use as a counter staining and the slides were visualized under light microscope. The quantification of staining was performed using image analysis software (Image J, 1.46a, NIH, USA).

\section{Histopathological assessment}

Autopsy samples from all groups were taken from heart (mainly ventricle) and fixed in $10 \%$ formalin for 4-7 days, followed by dehydration, clearing and embedding in paraffin. Sections were cut 4-6 $\mu \mathrm{m}$ and stained with H\&E.

\section{Statistical analysis}

Values were expressed as mean \pm SD. One-way ANOVA followed by Tukey's test Multiple Comparison Test were used to assess differences between groups. Categorical data was compared using a chi-square test. All statistical analysis was done using GraphPad Prism (GraphPad Prism software, version 5). The differences were considered significant when the calculated $\mathrm{P}<0.05$. Correlation analyses were performed with the help of the Pearson's correlation coefficients.

\section{Results}

\section{ECG}

ECG tracing showed normal cardiac activity in the control and SL per se treated rats. Rats in ISO-treated 
group showed significant increase in the heart rate by $28 \%$ compared to the control group with significantly increased elevated ST segment frequency from $12.5 \%$ in the control to $87.5 \%$ in ISO group. Such ECG abnormalities were obviously statistically improved in ISO intoxicated animals pretreated with sitaglibtin as evidenced by decreased HR by $22.7 \%$ as compared to ISO group and decreased the incidence of elevated ST segment within group to be $25 \%$ in ISO+ SL group (Figure 1).

\section{Cardiotoxicity markers}

Rats treated with ISO showed a significant increase in the relative heart weight by $21.2 \%$ compared to the control group. On the other hand, pretreatment with SL decreased it by $20 \%$ as compared to ISO animals. SL alone did not modify the absolute and relative heart weights (Table 1). The activities of myocardial injury markers, CK-MB and troponin I, compared to the control group were significantly elevated in the ISO animals by 155 and $156 \%$ respectively. Pretreatment with SL in ISO intoxicated animals significantly reduced the activities of CK-MB and troponin I as compared to ISO animals. SL alone, when compared to the control group, did not show any significant changes in CK-MB and troponin I (Table 1).

\section{Assessment of oxidative stress markers}

As shown in Table 2, ISO treatment significantly reduced GSH level by $68.8 \%$ and increased MDA level by $181.7 \%$ as compared to the control group. Furthermore, ISO induced a significant decrease in the cardiac antioxidant enzyme activities SOD by $40.4 \%$ as compared to the control levels. Pretreatment with SL in ISO animals could significantly elevate the levels of both of GSH and SOD by $83.2 \%$ and $35 \%$ respectively and reduce the MDA levels by $40.5 \%$ as compared to ISO animals (table 2).

\section{Assessment of myocardial nucleotides}

Rats treated with isoproterenol as compared to the control values showed a significant decrease in myocardial ATP and ADP by $59.4 \%$ and $36.1 \%$ respectively, as well as significant decrease in ATP/ADP ratio by $37.2 \%$ (Figure 2 , table 3 ). SL pretreatment in ISO animals counteracted the decrease in ATP/ADP ratio induced by ISO approximately by $58.1 \%$ as compared with the ISO value (Figure 2). A significant negative correlation between ATP/ADP ratio and serum $\mathrm{CK}-\mathrm{MB}(\mathrm{r}=-0.49, \mathrm{p}<0.05)$ (figure $2 \mathrm{C}$ ).

\section{Anti-TNF- $\alpha$ effect}

The expression of myocardial TNF- $\alpha$ was estimated using immunohistochemical staining. Control group showed minimal immunostaining. ISO elevated the myocardial expression of TNF- $\alpha$ as shown by the intense brown staining while pretreatment of intoxicated animals with sitaglebtin prevented this elevation to a large extent. No changes in myocardial expression were observed in the group treated with sitaglebtin alone (figure 3A, 3B, 3C, 3D). The immunohistochemical staining was quantified as optical density (OD) of the stained regions using the image analysis software (figure 3E).

\section{Histopathological assessment}

To further characterize the cardiotoxicity induced by ISO, histopathological examination of heart tissues were done. Myocardial tissues from control and SL only treated rats showed normal architecture (Figure 4A, B). Histological examination of hearts from ISOintoxicated animals revealed marked myocardial degeneration in the form of myofibrillar loss, cytoplasmic vacuolization, inflammatory cell infiltration, and congestion (Figure 4C). Pretreatment of intoxicated animals with SL preserved the normal myocardium architecture with remaining some inflammatory cell infiltrations (Figure 4D).

Table (1): Effect of sitaglebtin (30 $\mathrm{mg} / \mathrm{kg} / \mathrm{day})$ on parameters of cardiotoxicity in isoproternol induced myocardial injury

\begin{tabular}{|l|c|c|c|}
\hline \multicolumn{1}{|c|}{ Groups } & Heart index & CK-MB (IU/L) & Troponine I (ng/ml) \\
\hline Control & $0.33 \pm 0.03$ & $89.83 \pm 8.6$ & $1.083 \pm 0.29$ \\
\hline sitaglebtin & $0.33 \pm 0.04^{\mathrm{b}}$ & $95.5 \pm 6.2^{\mathrm{b}}$ & $1.117 \pm 0.37^{\mathrm{b}}$ \\
\hline ISO & $0.40 \pm 0.02^{\mathrm{a}}$ & $229.2 \pm 39.3^{\mathrm{a}}$ & $2.783 \pm 0.58^{\mathrm{a}}$ \\
\hline ISO+seaglebtin & $0.32 \pm 0.04^{\mathrm{b}}$ & $140 \pm 29.9^{\mathrm{b}}$ & $1.443 \pm 0.35^{\mathrm{b}}$ \\
\hline
\end{tabular}

Data are expressed as mean $\pm S D(n=8)$. ISO isoproternol, $C K-M B$ creatine kinase; a or b significantly different from the normal control or ISO injected rats respectively at $P<0.05$ using ANOVA followed by Tukey-Kramer as a post hoc test.

Table (2): Effect of sitaglebtin (30 mg/kg/day) on oxidative stress in isoproternol induced myocardial injury

\begin{tabular}{|l|c|c|c|}
\hline \multicolumn{1}{|c|}{ Parameters } & MDA (nmol/g tissue) & GSH $(\boldsymbol{\mu m o l} / \mathbf{g}$ tissue) & SOD ( $\boldsymbol{\mu g} / \mathbf{g}$ tissue) \\
\hline Control & $20.25 \pm 4.9$ & $0.635 \pm 0.17$ & $23.85 \pm 2.8$ \\
\hline sitaglebtin & $19.97 \pm 4.4^{\mathrm{b}}$ & $0.5367 \pm 0.05^{\mathrm{b}}$ & $24.75 \pm 2.8^{\mathrm{b}}$ \\
\hline ISO & $57.05 \pm 5.6^{\mathrm{a}}$ & $0.1983 \pm 0.05^{\mathrm{a}}$ & $14.22 \pm 3.6^{\mathrm{a}}$ \\
\hline ISO + sitaglebtin & $33.97 \pm 5.4^{\mathrm{b}}$ & $0.3633 \pm 0.04^{\mathrm{b}}$ & $19.2 \pm 2.6^{\mathrm{b}}$ \\
\hline
\end{tabular}

Data are expressed as mean $\pm S D(n=8)$. ISO isoproternol, SOD Superoxide dismutase, GSH Reduced glutathione, MDA Malondialdehyde; $a$ or $b$ significantly different from the normal control or ISO injected rats respectively at $P<0.05$ using ANOVA followed by Tukey-Kramer as a post hoc test. 
Table (3): Effect of sitaglebtin (30 mg/kg/day) on ATP, ADP, ATP/ADP in isoproternol induced myocardial injury

\begin{tabular}{|l|c|c|c|}
\hline \multicolumn{1}{|c|}{ Groups } & ATP $(\boldsymbol{\mu m o l} / \mathbf{g}$ tissue $)$ & ADP $(\boldsymbol{\mu m o l} / \mathbf{g}$ tissue $)$ & ATP/ADP \\
\hline Control & $0.35 \pm 0.05$ & $1.67 \pm 0.21$ & $0.216 \pm 0.05$ \\
\hline sitaglebtin & $0.35 \pm 0.05^{\mathrm{b}}$ & $1.73 \pm 0.16^{\mathrm{b}}$ & $0.2 \pm 0.04^{\mathrm{b}}$ \\
\hline ISO & $0.14 \pm 0.03^{\mathrm{a}}$ & $1.065 \pm 0.122^{\mathrm{a}}$ & $0.136 \pm 0.03^{\mathrm{a}}$ \\
\hline ISO+seaglebtin & $0.29 \pm 0.049^{\mathrm{b}}$ & $1.3 \pm 0.151^{\mathrm{b}}$ & $0.22 \pm 0.03^{\mathrm{b}}$ \\
\hline
\end{tabular}

Data are expressed as mean $\pm S D(n=8)$. ISO isoproternol, $C K-M B$ creatine kinase; a or b significantly different from the normal control or ISO injected rats respectively at $P<0.05$ using ANOVA followed by Tukey-Kramer as a post hoc test.

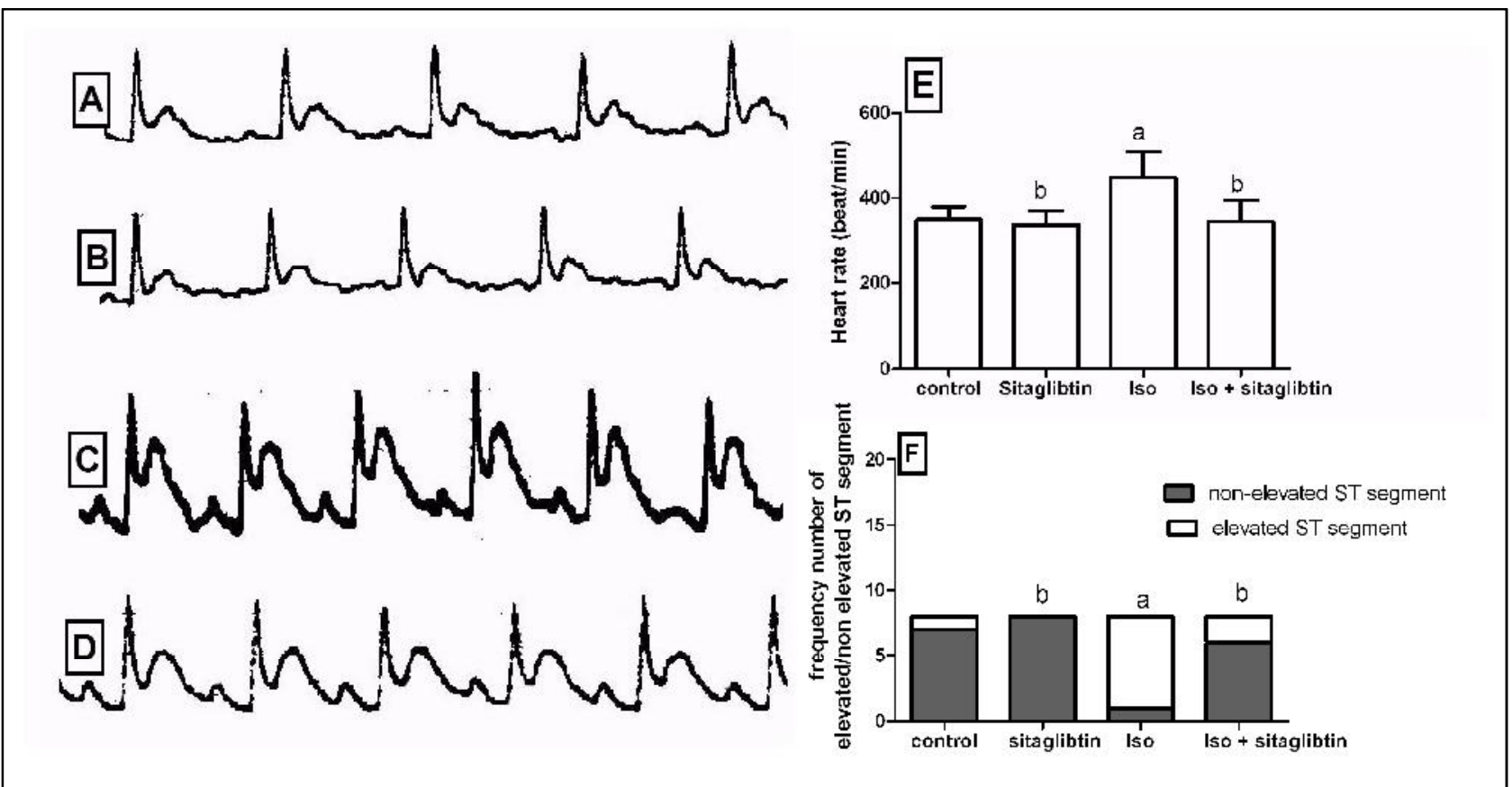

Figure (1): Effect of sitaglibtin pretreatment on ISO-induced myocardial injury in ECG pattern. (A) Control group, (B) sitaglibtin (30 mg/kg) treated group, (C) ISO (85 mg/kg) treated group, (D) sitaglibtin (30 mg/kg). ECG tracings of control and sitaglitbin-only treated rats show normal pattern. ISO-treated group shows tachycardia, elevation in ST segment. Sitaglibtin pretreatment in ISO intoxicated rats significantly decrease heart rate, ST segment elevation. (E) Heart rate data are expressed as mean \pm SD (n=8). (F) Frequency of elevated to non-elevated ST segment. a or b means significantly different from the normal control or ISO injected rats respectively at $\mathbf{P}<\mathbf{0 . 0 5}$ using ANOVA followed by Tukey-Kramer as a post hoc test. For frequency data a chi-square test was used. 


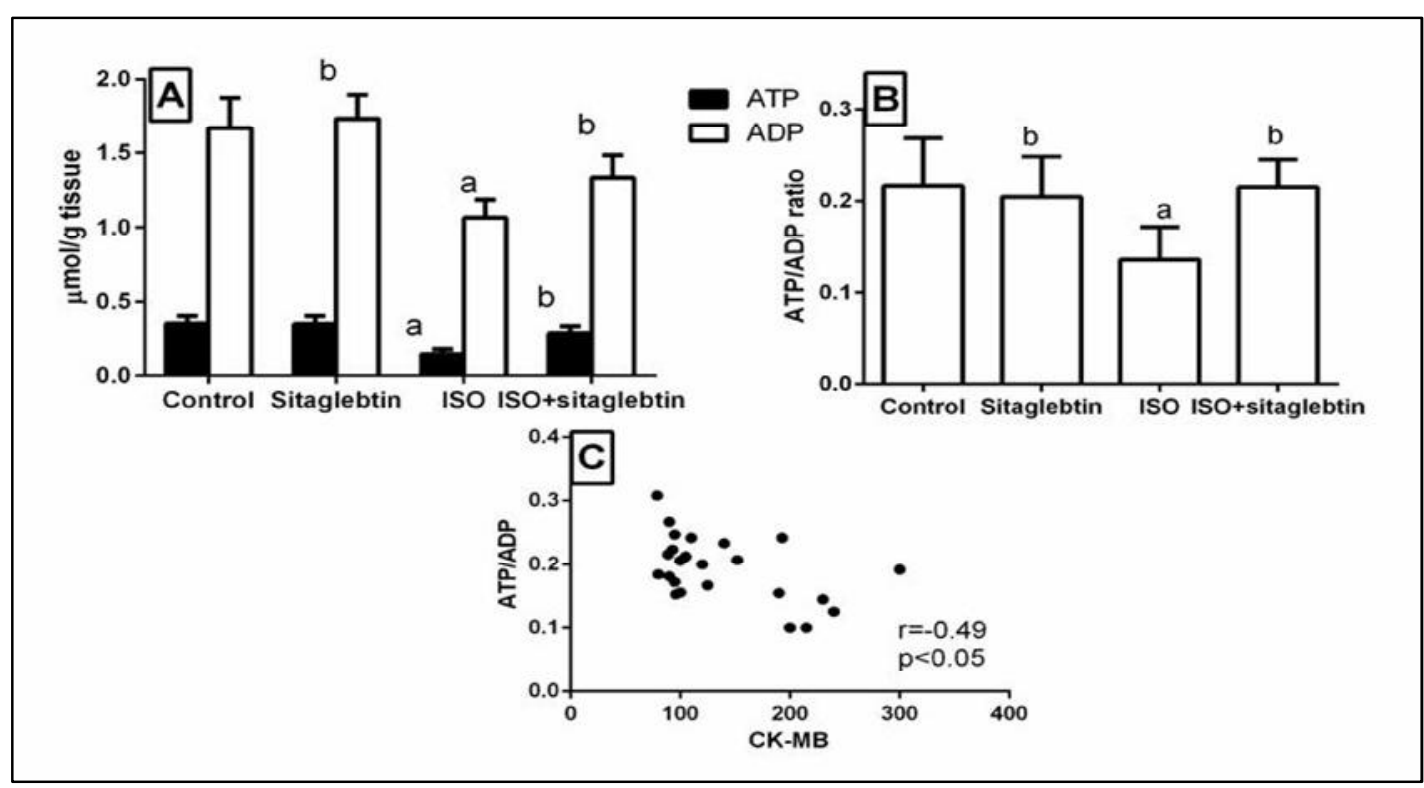

Figure (2): Effect of sitaglibtin pretreatment on ISO-induced myocardial injury (A) myocardial nucleotide ATP and ADP and (B) ATP/ADP ratio. (C) A correlation between serum cardiac enzyme CK-MB and ATP/ADP ratio. $n=8$, a and $b$ significantly different from the normal control or ISO injected rats respectively at $P<0.05$ using ANOVA followed by Tukey-Kramer as a post hoc test. Correlation analyses were performed with the help of the Pearson's correlation coefficients

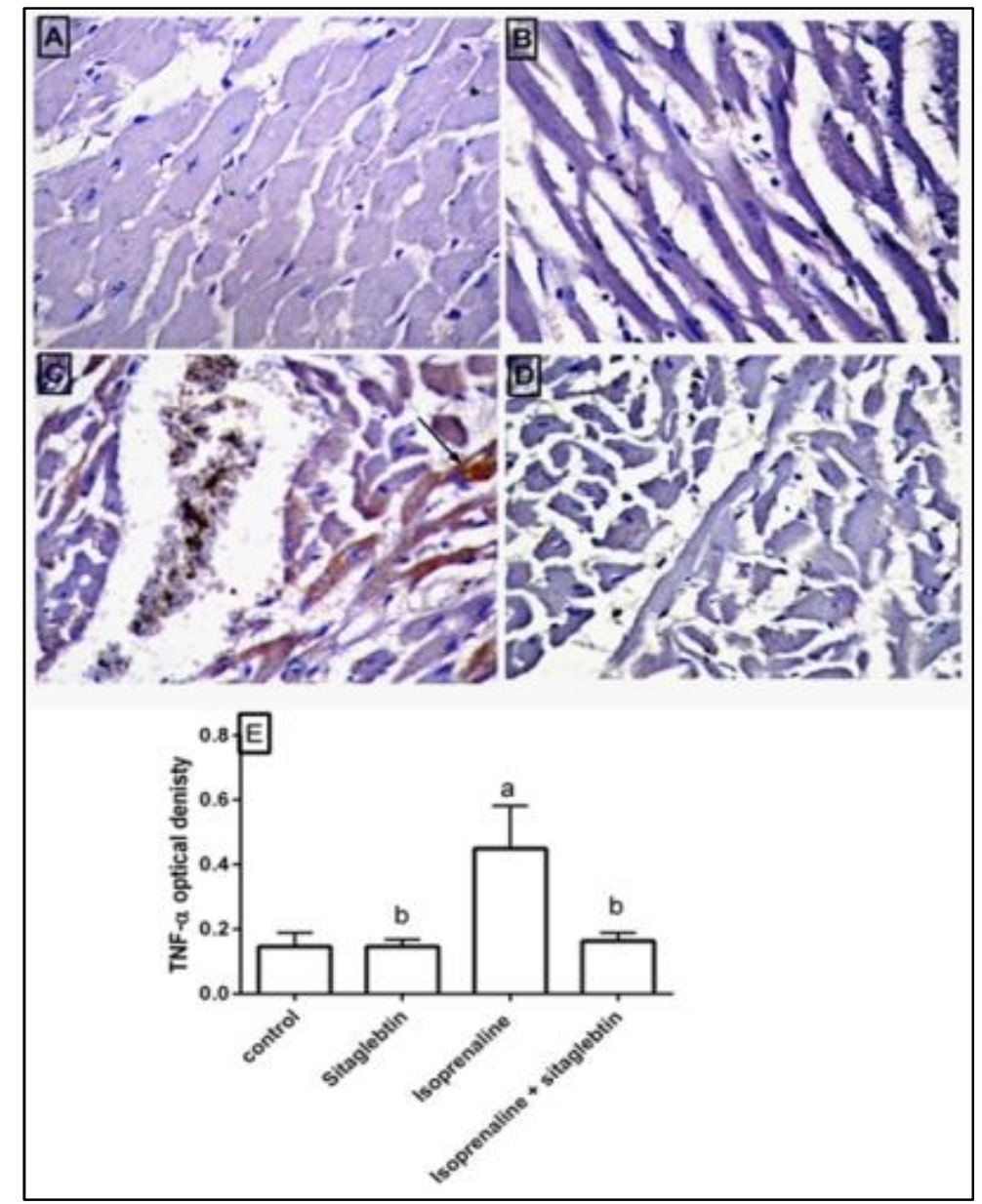

Figure (3): Effect of sitaglebtin pretreatment in isoproterenol induced myocardial injury on tissue TNF-a expression by immunohistochemical analysis of heart tissue (200×). (A) control group, (B) sitaglebtin (30mg/kg) treated group, (c) ISO intoxicated rats shows more immunostaining (arrow; brown colors), (d) sitaglebtin pretreatment in ISO intoxicated rats showed less staining, (E) graphic representation of optical density (mean \pm SD determined by direct visual counting of ten fields for each of three slides. $n=8$, a and $b$ significantly different from the normal control or ISO injected rats respectively at $\mathbf{P}<0.05$ using ANOVA followed by Tukey-Kramer as a post hoc test. 

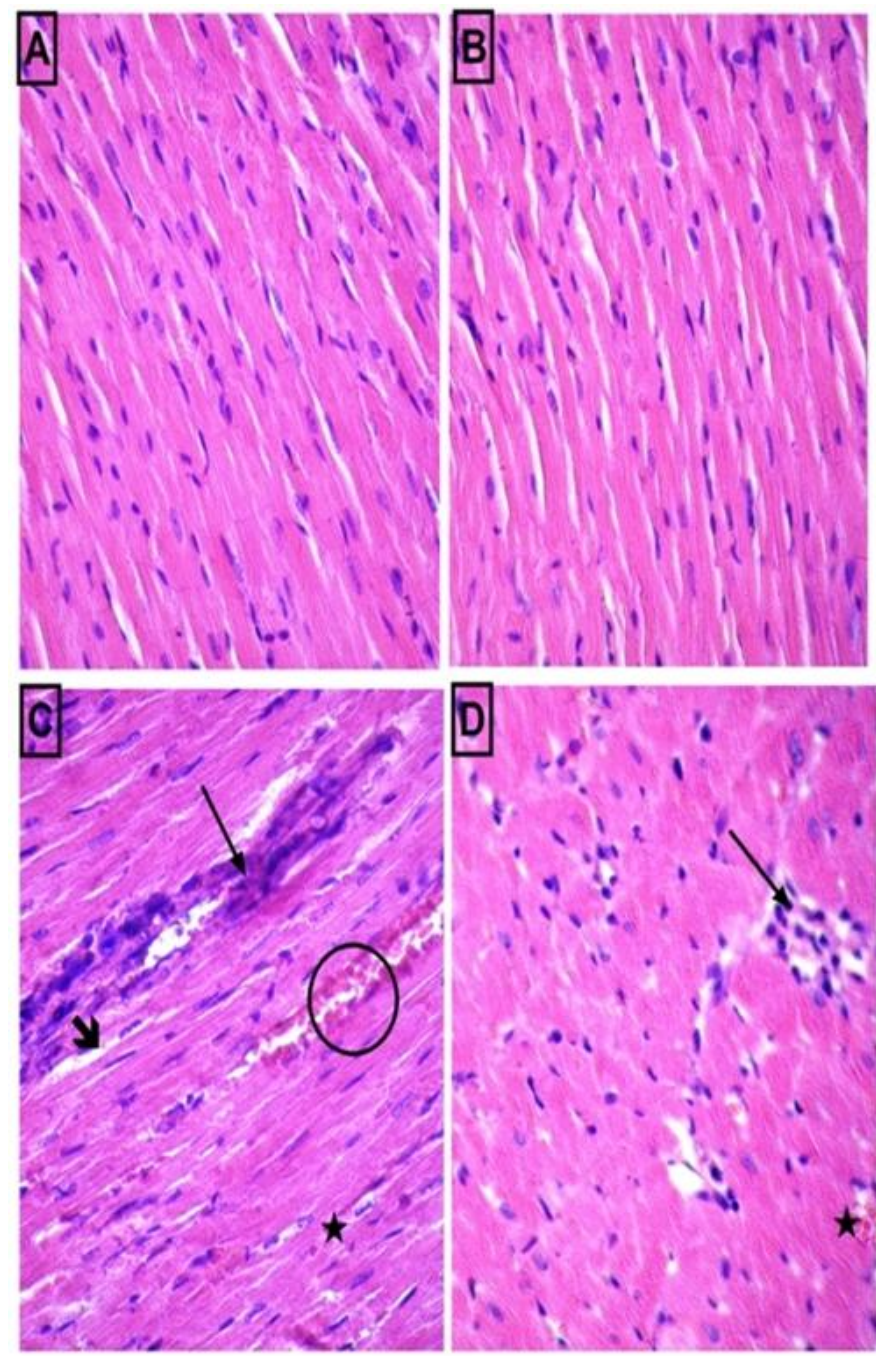

Figure (4): Effect of sitaglibtin pretreatment on ISO-induced histological alterations of the heart tissue (200×). Photomicrographs of haematoxylin and eosin stained sections of heart depicting (A) control group, (B) sitaglibtin $(30 \mathrm{mg} / \mathrm{kg}$ ) treated group, (C) ISO treated group, (D) sitaglibtin (30 mg/kg) pretreatment in ISO rats. (A) and (B) show normal histoarchitecture of the rat heart. (C) shows ISO-induced dilated congested blood vessels (circle), cytoplasmic vacuolization (stars) and inflammatory cell in filtration (long arrows). Widely separated muscle fibers leaving empty spaces between them (short arrow). (D) Shows that sitaglibtin pretreatment prevented cardiomyocyte damage induced by ISO where there was still some inflammatory cell in filtration (long arrows).

\section{Discussion}

DPP-4 inhibitors are newly available drugs approved for the treatment of type $2 \mathrm{DM}$ mainly by improving meal-stimulated insulin secretion by pancreatic $\beta$-cells, which is accomplished by sparing the hormone glucagon-like peptide-1 from degradation by the enzyme DPP-4 (Ahren et al., 2000). Glucagon-like peptide-1 receptors have been reported to be widely expressed in the heart and vasculature with specific localization in vascular endothelium/smooth muscle, endocardium and cardiomyocytes, suggesting that GLP-1 may play an important role in the cardiovascular system (Forst et al., 2012). Experimental data from animal and human studies indicate that GLP-1 has inotropic and vasodilatory effects, increased myocardial glucose uptake, improvement of endothelial function, reduction in infarct size, as well as potential anti-inflammatory and antiatherogenic actions (Goyal et al., 2010). Recent work has indicated that DPP4 inhibitor or glucagonlike peptide-1 (GLP-1) receptor agonists exert cardiovascular effects, such as modulation of heart rate, blood pressure, vascular tone and myocardial contractility (Okerson et al., 2014; Gill et al., 2010)

The present study was conducted to evaluate the possible protective effects of sitaglebtin (SL) against ISO-induced myocardial toxicity in rat. Moreover, to explore the possible mechanisms. ISOinduced myocardial injury was assessed by ECG, cardiac enzymes and histopathological examination of heart tissue. Significant alterations of ECG patterns were observed in ISO-intoxicated rats when compared with normal rats. The characteristic findings were the elevation of the ST segment, which might be an indicative sign of ischemia. ISO also increased the heart rate. Pretreatment with SL showed a protective effect against ISO- induced altered ECG patterns. This 
is Consistent with previous reports done by Apaijai and others who demonstrated that both vildagliptin and sitagliptin share similar efficacy in cardioprotection in obese insulin-resistant rats (Apaijai et al., 2013).

In addition, cardiac enzymes CK-MB and troponin I were increased with several histopathological changes in ISO intoxicated rats, which are in accordance with previous studies (Murray et al., 2000). Cardiac troponin I has been shown to be specific and sensitive biomarker of drug-induced myocardial cell injury in animals (Wallace et al., 2004). In rats, a number of studies have described a relationship between the serum levels of cardiac troponin I and the severity of ISO-induced myocardial injury (Bertinchant et al. 2000). When myocardial cells, containing cardiac enzymes are damaged due to ischemia, the cell membrane becomes permeable, which results in the leakage of enzymes. This accounts for the increased activities of these enzymes in serum. In patients, troponin provides an information about the severity of myocardial ischemia (Van Der Laarse, 2002). ISO-induced myocardial alterations are similar in certain respects to those occurring in human beings following a myocardial infarction (Zhang et al., 2008). In the present study, SL pretreatment prevented the changes in heart index and cardiac enzymes induced by ISO, indicating its beneficial cardioprotective effect. In a previous pilot study showed that the addition of dipeptidyl peptidase-4 inhibitor therapy with sitagliptin to the treatment regime of patients with type 2 diabetes mellitus and coronary artery disease is associated with a sustained improvement in myocardial performance during dobutamine stress and a reduction in postischemic stunning (McCormick et al., 2014).

It has been previously reported that, caecholamines produce quinones with subsequent myocardial Oxidative damage. So oxidative stress and apoptosis may contribute in the pathogenesis of these changes (Mann, 1998; Remiao et al., 2001). It is thought that the $\beta$ adrenergic cardiac stimulating activity exerted by ISO increases cardiac oxidative metabolism to a level that exceeds the amount of oxygen available to the myocyte through the unobstructed coronary circulation leading to energy imbalance (Van Vleet et al. 2002). The left ventricular subendocardium is the most susceptible area to hypoxia caused by tachycardia (Van Vleet et al., 2002). In the present work, ISO intoxicated rats showed a significant increase in myocardial lipid peroxides and significant decreases in GSH and SOD activities as compared with the control group. Pretreatment with SL in ISO intoxicated animals ameliorated these changes. Ferreira and others showed a remarkable positive impact of chronic sitaglebtin treatment at dose of $10 \mathrm{mg} / \mathrm{kg} /$ day on lipid peroxidation in both the pancreas and the heart in animal model of type 2 DM (Ferreira et al., 2010). This might be a further advantage in the management of diabetes and its proatherogenic comorbidities.
A state of energy starvation was observed in the present study as proved by a significant decrease in myocardial ATP, ADP and ATP/ADP ratio as compared to the control, this was in accordance with previous report by Chagoya de Sanchez et al (Chagoya de Sanchez et al., 1997). SL induced a significant increase in ATP/ADP ratio as compared with ISO group. Furthermore, a significant negative correlation between ATP/ADP ratio and CK-MB. Thus not only the antioxidant properties of SL could explain the cardiprotective effect but also its enhancement effect on the cellular energy. A constant re-synthesis of ATP by oxidative phosphorylation in the mitochondria is essentially needed to maintain proper function and calcium utilization by myocytes (Zhang, 2002).

Inflammation is a key pathophysiologic factor in diabetic cardiomyopathy (Cas et al., 2013). Biomarkers of inflammation including TNF- $\alpha$ levels is associated with risk of developing type 2 diabetes (Ti et al., 2011). ISO, was known to induce expression the myocardial inflammatory mediators as TNF- $\alpha$, IL- 6 , and IL-1 $\beta$ (Murray et al., 2002). A direct effect of TNF- $\alpha$ on cardiac hypertrophy in cultured cardiomyocytes was previously studied (Nakamura et al., 1998). TNF- $\alpha$ is likely to be important factors in the induction of hypertrophy (Yokoyama et al., 1997; Sekiguchi et al., 2004). In the present study, ISO intoxication significantly increased TNF- $\alpha$ expressions reflecting amplified inflammatory response. SL pretreatment significantly reduced its expression, indicating an anti-inflammatory effect. Our results coincided with previous studies that have reported that SL reduced the pro-inflammatory cytokines in macrophages, visceral adipose tissue, and atherosclerotic plaques (Vittone et al., 2012).

\section{Conclusion}

Taken together, the study indicate that sitagliptin, pretreatment could reduce myocardial injury and improve cardiac function in ISO induced myocardial injury by reducing oxidative damage, $\mathrm{TNF}-\alpha$, energy decline.

\section{No conflicts of interest.}

\section{Acknowledgment}

Thanks to the following individuals for their support to this work: Dr. Hatem S Shalaby, Nahla M Awad in the oncology, diagnostic unit, El Demerdash hospital.

\section{References}

Ahren B, Holst JJ, Martensson H and et al. (2000): Improved glucose tolerance and insulin secretion by inhibition of dipeptidyl peptidase IV in mice. Eur. J. Pharmacol. 404: 239-245.

Apaijai N, Pintana H, Chattipakorn SC and et al. (2012): Cardioprotective effects of metformin and vildagliptin in adult rats with insulin 
resistance induced by a high- fat diet. Endocrinology 153(8):3878-3885.

Apaijai N, Pintana H, Chattipakorn SC and et al. (2013): Effects of vildagliptin versus sitagliptin, on cardiac function, heart rate variability and mitochondrial function in obese insulin-resistant rats. Br J Pharmacol. 169: 1048-1057.

Arakawa M, Mita T, Azuma K and et al. (2010): Inhibition of monocyte adhesion to endothelial cells and attenuation of atherosclerotic lesion by a glucagon-like peptide-1 receptor agonist, exendin-4. Diabetes 59(4): 1030-1037.

Aschner P, Kipnes MS, Lunceford JK and et al. (2006): Effect of the dipeptidyl peptidase-4 inhibitor sitagliptin as monotherapy on glycemic control in patients with type 2 diabetes. Diabetes Care 29: 2632-2637.

Barakat GM, Nuwayri-Salti N, Kadi LN and et al. (2011): Role of glucagon-like peptid e-1 and its agonists on early prevention of cardiac remodeling in type 1 diabetic rat hearts. Gen. Physiol. Biophys. 30(1):34-44

Bertinchant JP, Robert E, Polge A and et al.(2000): Comparison of the diagnostic value of cardiac troponin I and $\mathrm{T}$ determination for detecting early myocardial damage and the relationship with histological findings after isoproternolinduced cardiac injury in rats. Clin. Chim. Acta. 298:13-28.

Cas AD, Spigoni V, Ridolfi V and et al. (2013): Diabetes and chronic heart failure: from diabetic cardiomyopathy to therapeutic approach. Endocr Metab Immune Disord Drug Targets, 15 (1): 220-223

Chagoya de Sanchez V, Hernandez-Munoz R, LopezBarrera F and et al. (1997): Sequential changes of energy metabolism and mitochondria function in myocardial infarction induced by isoproterenol in rats: a long-term and integrative study. Can. J. Physiol. Pharmacol. 75:1300-1311.

Charbonnel B, Karasik A, Liu J and et al. (2006): Efficacy and safety of the dipeptidyl peptidase-4 inhibitor sitagliptin added to ongoing metformin therapy in patients with type 2 diabetes inadequately controlled with metformin alone. Diabetes Care 29:26382643.

Chaykovska L, von Websky K, Rahnenfuhrer J and et al. (2011): Effects of DPP-4 inhibitors on the heart in a rat model of uremic cardiomyopathy. PLoS One 6(11):e27861.

Chen B, Moore A, Escobedo LVand et al. (2011): Sitagliptin lowers glucagon and improves glucose tolerance in prediabetic obese SHROB rats. Exp. Biol. Med. (Maywood) 236(3):309-314.
Drucker DJ, Sherman SL, Gorelick FS and et al. (2010): Incretin based therapies for the treatment of type 2 diabetes: Evaluation of the risks and benefits. Diabetes care 33(2): 428433.

Duckworth W, Abraira C, Moritz T and et al. (2009): Glucose control and vascular complications in veterans with type 2 diabetes. N. Engl. J. Med. 360:129-39.

El-Bassossy HM, Elberry AA, Azhar A, Ghareib SA and Alahdal AM (2015): Ameliorative Effect of Allopurinol on Vascular Complications of Insulin Resistance. Journal of Diabetes Research 2015, Article ID 178540, 10 pages.

Ellman GL (1959): Tissue sulfhydryl groups. Arch. Biochem. Biophys. 82(1): 70-77.

Ferreira L, Teixeira-de-Lemos E, Pinto $F$ and et al. (2010): Effects of Sitagliptin treatment on dysmetabolism, inflammation, and oxidative stress in an animal model of type 2 diabetes (ZDF Rat). Mediators of Inflammation 2010: 592760.

Forst T, Weber MM and Pfützner A (2012): Cardiovascular benefits of GLP1-based therapies in patients with diabetes mellitus type 2: effects on endothelial and vascular dysfunction beyond glycemic control. Exp. Diabetes Res. 2012: 635472.

Gill A, Hoogwerf BJ, Burger J and et al. (2010): Effect of exenatide on heart rate and blood pressure in subjects with type 2 diabete smellitus: a double-blind, placebo-controlled, randomized pilot study. Cardiovasc. Diabetol. 9:6.

Goyal S, Kumar S, Bijjem KV and et al. (2010): Role of glucagon-like peptide-1 in vascular endothelial dysfunction. Indian J. Exp. Biol. 48:61-69.

Laing SP, Swerdlow AJ, Carpenter LM and et al. (2003): Mortality from cerebrovascular disease in a cohort of 23000 patients with insulin-treated diabetes. Stroke 34:418 -421.

Mann DL (1998): Basic mechanisms of disease progression in the failing heart: the role of excessive adrenergic derive. Prog. Cardiovasc. Dis. 41(1): 1-8.

McCormick. LM, Kydd AC, Read PA and et al. (2014): Chronic dipeptidyl peptidase-4 inhibition with sitagliptin is associated with sustained protection against ischemic left ventricular dysfunction in a pilot study of patients with type 2 diabetes mellitus and coronary artery disease. Circ. Cardiovasc. Imaging 7(2):274-281.

Mihara M and Uchiyama M (1978): Determination of malonaldehyde precursor in tissues by thiobarbituric acid test. Anal Biochem. 86 (1): 271-278.

Miki T, Itoh T, Sunaga D and et al. (2012): Effects of diabetes on myocardial infarct size and 
cardioprotection by preconditioning and postconditioning. Cardiovasc. Diabetol. 11:67.

Murray DR, Prabhu SD and Chandrasekar B (2000): Chronic beta-adrenergic stimulation induces myocardial pro-inflammatory cytokine expression. Circulation101:2338-2341.

Murugesan M and Manju V (2013): Luteolin promotes mitochondrial protection during acute and chronic periods of isoproterenol induced myocardial infarction in rats. The Egyptian Heart Journal 65 (4): 319-327

Nakamura K, Fushimi K, Kouchi H and et al. (1998): Inhibitory effects of antioxidants on neonatal rat cardiac myocyte hypertrophy induced by tumor necrosis factor-alpha and angiotensin II. Circulation 98(8):794-799.

Nauck MA, Kleine N, Orskov C and et al. (1993): Normalization of fasting hyperglycaemia by exogenous glucagon-like peptide 1(7-36 amide) in type 2 (non-insulin-dependent) diabetic patients. Diabetologia 36(8):741 744.

Neri B, Cini-Neri G, Bartalucci S and et al. (1986): Protective effect of 1-carnitine on cardiac metabolic damage induced by doxorubicin in vivo. Anticancer Res. 6: 659-662.

Nikolaidis LA, Elahi D, Hentosz T and et al. (2004): Recombinant glucagon-like peptide-1 increases myocardial glucose uptake and improves left ventricular performance in conscious dogs with pacing-induced dilated cardiomyopathy. Circulation 110(8):955-961.

Okerson T, Yan P, Stonehouse A and et al. (2014): Effects of exenatide on systolic blood pressure in subjects with type 2 diabetes. Am J Acta Cardiol. Sin. 30:29-37

Pacheco BP, Crajoinas RO, Couto GK and et al. (2011): Dipeptidyl peptidase IV inhibition attenuates blood pressure rising in young spontaneously hypertensive rats. J. Hypertens. 29(3):520-528.

Patil VC, Patil HV, Shah KB and et al. (2011): Diastolic dysfunction in asymptomatic type 2 diabetes mellitus with normal systolic function. J. Cardiovasc. Dis. Res. 2(4):213222.

Remiao F, Carmo H, Carvalho F and et al. (2001): Copper enhances isoproterenol toxicity in isolated rat cardiomyocytes: effects on oxidative stress. Cardiovasc. Toxicol. 1:195204.

Sekiguchi K, Li X, Coker M and et al. (2004): Crossregulation between the renin-angiotensin system and inflammatory mediators in cardiac hypertrophy and failure. Cardiovasc. Res. 63(3):433-442.

Shim WS, Kim HJ, Kang ES and et al. (2006): The association of total and differential white blood cell count with metabolic syndrome in type 2 diabetic patients. Diabetes Res. Clin. Pract. 73: 284-291.

Snell-Bergeon JK and Wadwa RP (2012): Hypoglycemia, diabetes, and cardiovascular disease. Diabetes Technol Ther.14 (1): S51-8.

Sumita Yoshikawa W, Nakamura K, Miura D and et al. (2012): Increased Passive Stiffness of Cardiomyocytes in the Transverse Direction and Residual Actin and Myosin Cross-Bridge Formation in Hypertrophied Rat Hearts Induced by Chronic beta-Adrenergic Stimulation. Circ. J. 77 (3):741-748.

Ti Y, Xie GL, Wang ZH and et al. (2011): TRB3 gene silencing alleviates diabetic cardiomyopathy in a type 2 diabetic rat model. Diabetes, 60 (11): 2963-2974

Van Der Laarse A (2002): Hypothesis: troponin degradation is one of the factors responsible for deterioration of left ventricular function in heart failure. Cardiovas. Res. 56: 8-14.

Van Vleet JF, Ferrans JV and Herman E (2002): Cardiovascular and skeletal muscle system. In: Haschek and Rousseaux's Handbook of Toxicologic Pathology, Haschek WM, Rousseaux CG, Walling MA, et al. (eds),3rd ed., academic Press, San Diego, CA, USA, 2, pp 363-455

Vittone F, Liberman A, Vasic D and et al. (2012): Sitagliptin reduces plaque macrophage content and stabilizes arteriosclerotic lesions in Apoe (-/-) mice. Diabetologia 55(8):22672275.

Wallace KB, Hausner E, Herman E and et al.(2004): Serum troponins as biomarkers of druginduced cardiac toxicity. Toxicol. Pathol. 32:106-121.

Xiao YF, Nikolskaya A, Jaye DA and et al. (2011): Glucagon-like peptide-1 enhances cardiac Ltype $\mathrm{Ca} 2+$ currents via activation of the cAMP-dependent protein kinase A pathway. Cardiovascular Diabetology 10:6.

Yokoyama T, Nakano M, Bednarczyk JL and et al. (1997): Tumor necrosis factor-alpha provokes a hypertrophic growth response in adult cardiac myocytes. Circulation 95(5):1247-52.

Zhang J (2002): Myocardial energetics in cardiac hypertrophy. Clin. Exp. Pharmacol. Physiol. 29: 351-359.

Zhang J1, Knapton A, Lipshultz SE and et al. (2008): Isoproterenol-induced cardiotoxicity in sprague-dawley rats: correlation of reversible and irreversible myocardial injury with release of cardiac troponin $\mathrm{T}$ and roles of iNOS in myocardial injury. Toxicol. Pathol. 36(2):2778. 


\section{الملخص العربي}

الآلية الوقائية لدواء السيتاجلبتين ضد إصابة عضلة القلب الناتجة عن الايزوبروتيرنول في الجر ذان

$$
\text { وسام البقلي' }
$$

إن دواء السيتاجلبتين (هو أحد أدوية مرض السكر والتي تعمل كمثبط للأنزيم الدايبيبتيديل بيبتيداز) يقلل من الدهون الثلاثية والدهون

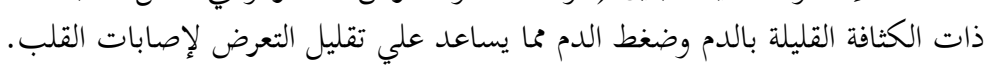

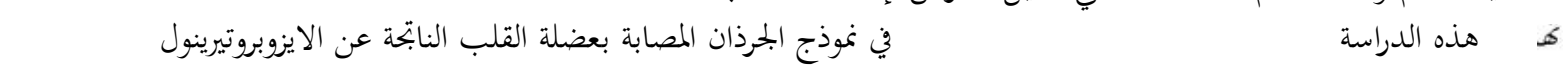

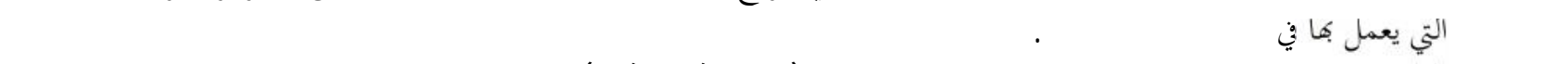

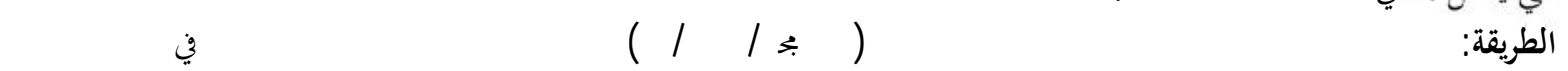

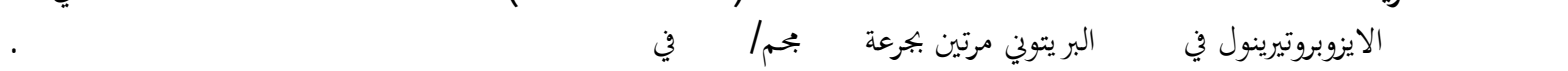

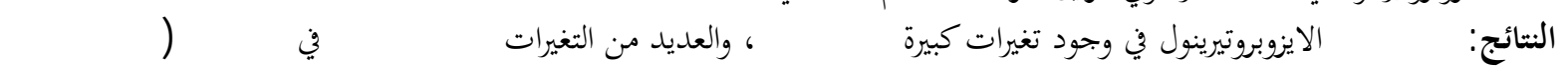

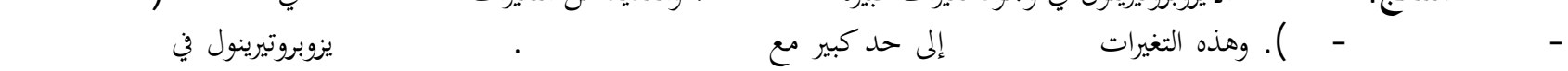

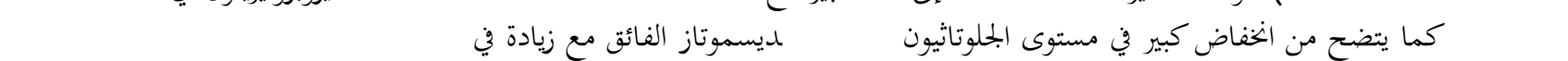

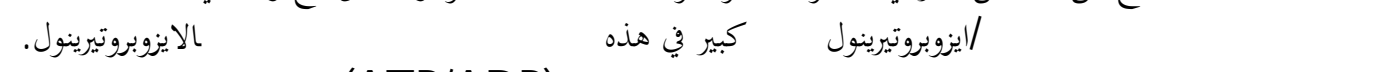

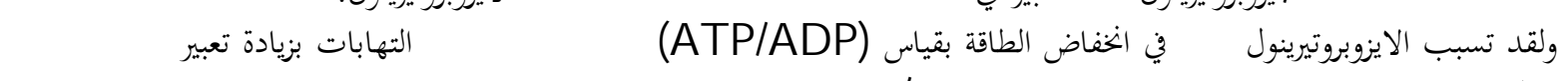

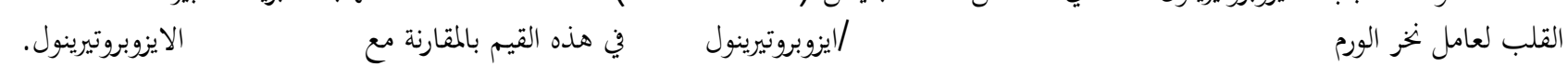

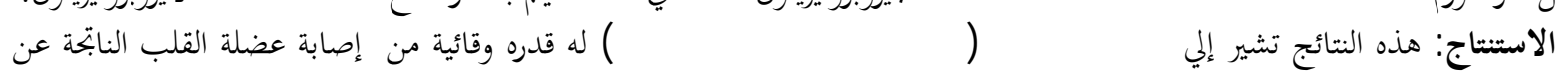

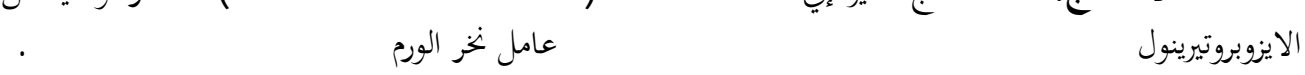

